\title{
POLÍTICAS DE REGULAÇÃO E MERCANTILIZAÇÃO DA EDUCAÇÃO: SOCIALIZAÇÃO PARA UMA NOVA CIDADANIA?
}

\author{
Nora Rut KraWcZyK*
}

\begin{abstract}
RESUMO: O texto analisa, a partir de reflexōes teóricas e pesquisas empíricas, um dois eixos principais da reforma educativa ocorrida nos anos de 1990 na América Latina. Isto é, a consolidação de uma nova organização e gestão do sistema educativo e da escola, que define formas quase mercantis de delegação de poderes. Esse novo modelo de regulação supõe uma mudança radical da categoria 'sociedade civil' e 'cidadania' e vem sendo concretizado a partir de um processo de descentralização desenhado em três dimensões: descentralização entre os diferentes órgãos de governo (municipalização), descentralização para escola (autonomia escolar) e descentralização para o mercado (responsabilidade social). Busca-se analisar a concepção da reforma educacional no marco de um novo ordenamento das relaçôes internacionais e da reconfiguração do modelo de Estado provedor e regulador para o modelo de Estado forte e minimalista e, principalmente, enquanto expressão da lógica dos binômios globalização/comunitarismo e centralismo/localismo.
\end{abstract}

Palavras chaves: Reforma educacional. Cidadania. Sociedade civil. América Latina. Gestão educacional.

\section{REGULATION POLICIES AND THE MERCANTILIZATION OF EDUCATION: SOCIALIZATION TOWARDS A NEW CITIZENSHIP?}

ABSTRACT: Based on theoretical reflections and empirical research, this paper analyzes one of the main drives of the educational reform that took place in the 1990s in Latin America: the consolidation of a new organization and administration of the educational system and of school, which defines almost mecantile forms of power del-

Doutora em educação e professora do Departamento de Ciências Sociais Aplicadas à Educação (DECISAE) da Faculdade de Educação da Universidade Estadual de Campinas (UNICAMP). E-mail: norak@uol.com.br

Educ. Soc., Campinas, vol. 26, n. 92, p. 799-819, Especial - Out. 2005 
Políticas de regulação e mercantilização da educação...

egation. This new regulation model supposes a radical change in the 'civil society' and 'citizenship' categories and is carried out through a three dimension decentralization process: decentralization among different governments agencies (municipalization), decentralization toward schools (school autonomy) and decentralization toward the market (social responsibility). It tries to analyze the conception of the educational reform in the framework of a new arrangement of the international relationships, and of a reconfiguration from the model of a regulating Welfare State to the that of a strong, minimalist State and mainly as the expression of the logics of the binomials globalization/communitarism and centralism/localism.

Key words: Educational Reform. Citizenship. Civil society. Latin America. Educational administration.

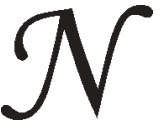

a época contemporânea, a cidadania moderna aparece ligada à conformação de um sujeito de direito e este à existência de um Estado que garanta esse direito. Mas também, e principalmente, à luta social pelas conquistas desses direitos que gerou a exigência de igualdade cidadã. No entanto, no momento em que as funções do Estado se restringem à regulação do mercado - transferindo para a sociedade civil responsabilidades sobre a área social, que passa a assumi-las enquanto iniciativa privada -, a igualdade cidadã volta a ser subordinada à possibilidade de acesso a estes direitos e um dos critérios mais evidentes é a condiçãao de pagar por esse direito. ${ }^{1}$

Seguramente, todos nós concordamos que a educação é um desses direitos; mas, ao mesmo tempo e em parte, está envolvido na instituição de outros direitos que, historicamente, definem a cidadania. Entretanto, a educação não constitui a cidadania, mas sim uma condição indispensável para que a cidadania se constitua. É assim que a tensão entre o potencial reprodutor e emancipador da educação escolar é constitutiva da natureza da relação entre educação e cidadania.

Historicamente, essa relação entre educação e cidadania foi se transformando em obrigação pela maioria dos Estados. E, em tese, seria garantida por um Estado provedor de políticas universalistas e regulador das desigualdades sociais que, por sua vez, possibilitariam um processo de socialização comum e de integração nacional. Nesse sentido, o Estado devia cumprir também um papel central na pretendida igualdade dos sujeitos na escolarização pública que, entre outras coisas, significava a abo- 
lição das diferenças econômicas e culturais no espaço escolar (Dussel, 2000). A atuação e a escolha individual e familiar ficaram bastante restringidas frente às aspirações estatais de controle institucional, de inclusão e de justiça social.

Dessa forma, configura-se na sociedade moderna um equilíbrio instável de poderes para influir na infância e na juventude, entre o Estado e a família (também com outros setores privados, como o empresarial, a Igreja etc.), atravessado por conflitos sobre as responsabilidades e atribuiçôes de uma e de outra. Uma configuração em que prevalecia o poder do Estado e à qual sempre resistiram os interesses privados, e acentuado na atualidade pela forte presença social da ideologia privatista, estimulando ainda mais esse conflito com o Estado (Gimeno, 1998).

No entanto, observam-se diferenças nas implantações dos sistemas educacionais nos diferentes países latino-americanos. Os projetos nacionais hegemônicos, as lutas e os compromissos das diferentes classes sociais são dimensões de análise fundamentais das trajetórias da educação pública nos diferentes países da região. Assim, por exemplo, no Chile o sistema de ensino (instituído em fins do século XIX) já pressupôs uma parceria com as sociedades civis, pela qual o ensino público não significaria necessariamente gratuidade, mas sim a perspectiva de atender a toda a demanda como forma de integração nacional (Krawczyk \& Vieira, 2003).

Institui-se, com esta perspectiva, a subvenção ao ensino, que pode advir de vários segmentos sociais e não apenas do Estado. Desde então, tal sistema vem sendo aperfeiçoado no sentido de atingir sempre as proposituras iniciais, às quais se acrescem outras a cada momento histórico. Já no Brasil, a relação entre o governo e a sociedade, desde a constituição de 1824, pressupõe o ensino público e gratuito, mas deixa brechas para que o ensino também possa ser privado. No entanto, isto não tornou a educação formal mais acessível para a maioria da população.

A educação primária e secundária no Brasil foi organizada sob a responsabilidade dos estados e/ou municípios, que posteriormente irão conformando várias redes de ensino em todo o país. $\mathrm{O}$ caráter descentralizado da educação formal no Brasil tem origem, principalmente, na omissão do poder público, no embate de diferentes projetos societários das elites locais; e, em menor importância, na organização federativa do país. Esses conflitos têm acompanhado também a lógica de distribuição 
Políticas de regulação e mercantilização da educação...

das competências entre as diferentes unidades de governo - União, estados e municípios - ao longo de todo o século XX até hoje.

Já no México, a revolução reificada no PRI reúne os diferentes segmentos da sociedade, à exceção dos camponeses nativos, que elegem o sistema educacional como integrante dos esforços para a consolidação da nação, embora sem encontrar os mecanismos para viabilizar tal meta, conforme se observa no Chile.

$\mathrm{Na}$ Argentina, uma das políticas mais importantes no século XIX de integração de sua população bastante heterogênea (porque estava constituída, principalmente, de imigrantes ou de filhos de imigrantes) foi a organização de um sistema educacional nacional. Contudo, a escola única e centralizada seria um elemento-chave na construção de uma identidade nacional unificada, não só porque permitiria a socialização dos filhos dos imigrantes a partir de valores, costumes e uma língua comuns, mas também porque estabeleceria a articulação entre a escola e a sociedade, anulando os localismos e o caudilhismo, afirmando o poder das elites nacionais frente às elites locais das províncias. A escola pública converteu-se, assim, num eficiente sistema de assimilação da população imigrante e provincial (Tedesco, 1982).

O rápido aumento do índice de escolarização primária e a formação docente centralizada são destacados por Tedesco (1982) como os meios pelos quais essas massas heterogêneas se integraram à sociedade argentina.

A resultante de tal diversidade na configuração do processo histórico de cada um destes países será a de que os diferentes segmentos da sociedade, ao longo de todo o século XX, apresentarão demandas distintas, constituindo-se inter-relaçóes específicas destes com o Estado.

Ora, o novo modelo de regulação que vem sendo instaurado nas últimas décadas - conseqüência da reconfiguração do modelo de Estado provedor e regulador para o modelo de Estado avaliador - aviva a presença do indivíduo e do mercado, interferindo não só no comportamento estatal, mas também no comportamento social.

Para o filosofo francês Gilles Lipovestisky, a segunda metade do século XX tem se caracterizado pela intensificação do tripé que sempre caracterizou a modernidade: o mercado, o indivíduo e a escalada técnicocientífica. $\mathrm{O}$ violento avanço da globalização, do ultraliberalismo e das novas tecnologias de comunicação nos anos 80 intensifica ainda mais esse 
tripé, produzindo o fenômeno da hipermodernidade - que afeta os comportamentos e modos de vida; e, ao mesmo tempo (e paradoxalmente) fragiliza o indivíduo, que vê desmoronar as antigas formas de coesão social.

A escola pública de massas na América Latina, além de reunir os princípios de igualdade e justiça social na sua estrutura e organização, passa a ser também responsável por transmiti-los. O processo contraditório de intensificação do indivíduo e do mercado, identificado por Lipovestisky, vem mudando esse comportamento institucional e privilegiando a heterogeneidade, a diferença e o individualismo.

A ideologia igualitária e seus ideais universalistas, que inspiraram a constituição e expansão dos sistemas educativos, que justificaram a atuação dos Estados nacionais e foram âncoras da luta pela democratização política e social, são agora revisados. $\mathrm{O}$ argumento de que os Estados nacionais têm demonstrado pouca capacidade - quantitativa e qualitativa - de investimento justifica a desvalorização da arrecadação em forma de impostos, a privatização e a imposição de uma nova lógica de regulação social.

De uma forma ou de outra, as reformas que se iniciam nesta época ocorrem sob a lógica da "modernização", seguindo a tendência de toda a região, isto é, adaptar a educação às mudanças econômicas e de concorrência internacional. Neste sentido, propõe-se inovar não só as relações institucionais no interior do próprio Estado (que se mantém na liderança da implementação das reformas), mas também as parcerias com a sociedade civil. ${ }^{2}$

Um dos eixos principais da reforma educacional, ocorrida nos anos 90 do século XX na América Latina, foi a consolidação de uma nova organização e governação ${ }^{3}$ do sistema educacional e da escola. Esta, ao adotar o princípio do mercado como indicador das realizações em todas as esferas sociais e ao ressignificar o conceito de cidadania enquanto consumidor, define formas quase mercantis de delegação de poderes e de relação com a demanda educacional.

Esse novo modelo de regulação está se concretizando na América Latina, entre outras políticas, a partir de um processo de descentralização bastante diferente do concebido tradicionalmente.

Em décadas anteriores, quando se falava em descentralização, pensava-se, principalmente, no processo de redistribuição de responsabilida- 
Políticas de regulação e mercantilização da educação...

des, atribuições e autonomia de decisão entre diferentes órgãos de governo. A reformulação da relação entre Estado e sociedade acarreta uma dinâmica descentralizadora de responsabilidade e atribuições mais complexa e envolve outras dimensóes que atuam conjuntamente. Além da dimensão territorial, que outorga novas funçōes aos governos central, estaduais ou provinciais e municipais, ${ }^{4}$ vamos encontrar, como inovação desse processo, a descentralização para a escola e a descentralização para o mercado (Krawczyk, 2002).

A possibilidade de realizar algumas reflexōes sobre estas questões, a partir de situaçôes específicas, surgiu de um balanço analítico que realizamos sobre a produção científica existente em países latino-americanos, relativamente a esta reforma educacional que se inicia na década de 1990 na regiāo (Krawczyk \& Vieira, 2005).

A política de descentralização entre os diferentes órgãos de governo anunciava, estabelecendo uma relação entre descentralizaçăo e autonomia, que a proximidade territorial entre o governo e a instituição escolar provocaria uma mudança na suas práticas de governança e na definição de suas relações internas de poder, entre outras. No entanto, isto não parece ter acontecido. Todavia, a gestão e o governo das unidades escolares foram realmente atingidos pela política de descentralização para a escola e para o mercado.

O olhar para a gestão da escola, sua autonomia e o aumento da participação da comunidade escolar não é novidade em alguns países latinoamericanos. Foi, por exemplo, um tema relevante nos finais da década de 1970, principalmente devido aos desafios colocados para a construção de uma sociedade democrática em vários paises da região, com destaque para o Brasil.

Nessa conjuntura, em alguns países, com maior ênfase que em outros, setores progressistas recriam a concepção da autogestão e/ou co-gestão como modelo de administração autônoma, advinda, entre outros, dos movimentos socialistas e libertários anarquistas. Como sabemos, a organização partidária e a dos trabalhadores sempre foram questōes bastante discutidas por eles, defendendo a coletivização e formas cooperativas de qualquer tipo de gestão institucional. Estas propostas sempre tomaram mais força no âmbito dos movimentos anarquistas, que, a diferença do movimento socialista, não tinham como preocupação a gestão do Estado - pelo contrário, se posicionaram contra todo tipo de poder, inclusive o poder estatal. 
A partir de finais dos anos 70 do século XX, a preocupação pela organização dos trabalhadores e dos espaços de trabalho passou a estar também presente na análise da organização escolar. Principalmente a idéia de que as condições de democratização da escola estão na possibilidade de auto-organização dos trabalhadores da educação, e no aumento do poder de influência desses trabalhadores e dos alunos nas decisões da instituição, que eliminariam a cisão entre gestão do trabalho e realização do trabalho (Tragtenberg, 1985; Bruno, 2002). Inicia-se, assim, uma discussão que nos anos seguintes vai ser rapidamente ressignificada no discurso hegemônico, mesmo antes de ter sido suficientemente amadurecida no debate político e acadêmico.

O tema da gestão escolar na reforma de 1990 mantém seu lugar de destaque; sofre, porém, uma inversão e uma mudança radical de sentido ao ser localizada como uma dimensão do processo de descentralização assumida oficialmente. Deixa de ser expressão da demanda da comunidade educativa por maior autonomia escolar, em busca de democratização das relações institucionais, para passar a ser resultado da preocupação dos órgãos centrais por redefinir quem deve assumir a responsabilidade da educação pública: tanto pela definição de seu conteúdo, como por seu financiamento e resultados.

Desta forma, assim como um dos pilares principais da Reforma é a gestão, o espaço privilegiado por ela é a unidade escolar, promovendo a autonomia - financeira, administrativa e pedagógica - da instituição.

A idéia da centralidade do âmbito escolar nas políticas educacionais parecia, numa primeira instância, recuperar a preocupação de muitos pesquisadores, principalmente no México e, em parte, também no Brasil. No entanto, as mudanças ocorridas ao longo das últimas décadas esclarecem a preocupação pela unidade escolar como centro de unidade financeira e de regulação social.

Ainda que várias das novas políticas implementadas na gestão escolar possam ter também o propósito de mudar a gestão pedagógica da escola, elas não tiveram impacto no cotidiano escolar, sendo privilegiados os câmbios na gestão financeira e administrativa e produzindo mudanças importantes na governação das instituições, ao incorporar a lógica do mercado na gestão pública (Krawczyk, 2003).

O México foi vanguarda na pesquisa etnográfica e na conceitualização do cotidiano escolar na região. Essa forte preocupação pela orga- 
Políticas de regulação e mercantilização da educação...

nização do trabalho escolar, como dimensão fundamental na compreensão dos processos educativos e de sua qualidade, leva-o a receber com entusiasmo o novo lugar outorgado pelo discurso político-educacional no início dos anos de 1990 à instituição escolar; por reconhecer a escola como dimensão atuante na produção do ensino; e romper, assim, com a tradição das reformas na região (Ezpeleta, 2003).

Assim, no marco dos debates que levaram ao Acuerdo Nacional para la Modernización de la Educación Básica, em 1992, colocou-se a necessidade de transformar o funcionamento da instituição escolar, pois existia o consenso de que a autoridade (federal e estadual) havia se distanciado, cada vez mais, da instituição, como conseqüência da centralização do sistema. E isso afetava a organização escolar com excessos de mecanismos burocráticos, excluindo a possibilidade de compartilhar a responsabilidade da educação das crianças com sua família e com a comunidade.

Entre as ações prioritárias, foi definido, também, o estabelecimento de um programa de reformas da organização e avaliaçãa da escola. A professora Justa Ezpeleta afirma ${ }^{5}$ que a qualidade na educação e a necessidade de melhorar a aprendizagem dos alunos não são temas novos entre as preocupaçóes educacionais no México, mas sempre se circunscreveram às propostas de mudanças no trabalho pedagógico, apontando principalmente as formas de ensinar e os conteúdos.

Nesse sentido, o projeto La gestión en la escuela primaria, implantado em 1997 com o apoio de Olac Fuentes Molinar, então sub-secretário de educação básica, traz como novidade a inclusão da organização e da administração da escola como elemento interveniente na produção do ensino. Pouco antes, a SEP tinha publicado um estudo da professora Silvia Shmelkes mostrando que o contexto socioeconômico não era um fator determinante da qualidade educativa - esta dependia do trabalho do diretor, dos professores, do compromisso dos pais e da relação da escola com a comunidade.

A partir dessas e de outras constatações, o projeto La gestión en la escuela primaria buscou priorizar a construção de um novo estilo de trabalho escolar coletivo que, a partir de uma proposta pedagógica de gestão, permitia a ruptura com as práticas clientelistas e cooperativistas consolidadas na gestão educacional mexicana. O projeto implicava uma forma inovadora de capacitação de professores, envolvendo a organização institucional e todo o sistema educativo - governos estaduais e organismos intermediários. 
Uma das preocupações mais compartilhadas entre os pesquisadores mexicanos é o atrelamento histórico da burocracia sindical com o Estado nacional e o controle e co-administração do sistema educativo. Por exemplo, os principais quadros do Sindicato Nacional de Trabalhadores da Educação (SNTE) fazem parte do aparelho administrativo da educação (situação que permaneceu mesmo com a queda do PRI), chegando a ponto de haver confusão, nos níveis intermediários do sistema educativo, acerca do que é o âmbito da representação sindical e a esfera da administração educativa.

O projeto La gestión en la escuela primaria foi perdendo importância na política educativa do presidente Fox, que assumiu como carro-chefe de sua gestão educacional o Programa Escuelas de Calidad (PEC).

Tendo como antecedente o projeto de gestão escolar, e a partir de outras experiências regionais similares na Colômbia, Argentina e Chile, foi desenhado o PEC - com a preocupação, claramente manifestada pelo próprio presidente, de criar escolas de qualidade e entregar-lhes os recursos com base no seu desempenho. O PEC considera a gestão escolar exclusivamente em sua dimensão administrativa e recupera a competitividade da gestão de recursos materiais das equipes escolares. Apropria-se de uma forma de trabalho coletivo de elaboração de planos institucionais, porém mudando seu sentido e intencionalidade.

Enquanto o projeto La gestión en la escuela primaria buscava elaborar coletivamente uma proposta para a escola, que permitisse devolver a cada um dos atores envolvidos o sentido de suas tarefas com os alunos, e gerar uma unidade escolar com identidade própria, o PEC se apropria da idéia do projeto escolar, mas o despoja de sua ambição de ser um processo de aprendizagem institucional, transformando-o numa ação de competição por recursos materiais entre as escolas.

Talvez o fato de a aprovação de novas diretrizes para a educação ter acontecido no início da década de 1990, por meio do Acuerdo Nacional para la Modernización de la Educación Básica, tenha permitido uma margem de ação política ainda não submetida à nova lógica de regulação social, que iria ser construída nos anos posteriores na região (como no caso do México com o PEC).

No Brasil, encontramos uma situação um pouco diferente. O debate em torno da autonomia escolar, que já vinha sendo colocado em oposição às estruturas administrativas centralizadas e burocratizadas impostas pelo governo militar, desenvolveu-se bastante na década de 1980 
Políticas de regulação e mercantilização da educação...

na busca de uma governação participativa, no quadro de luta pela construção de uma sociedade democrática e de formação do cidadão.

Esse acúmulo de discussão gerou pressupostos, princípios e propostas que influenciaram bastante o cenário controverso da política edu-

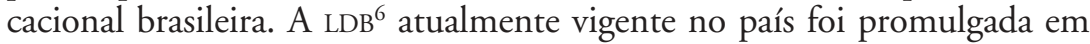
1996. O longo período transcorrido entre a sanção da Constituição de 1988 e a nova LDB deveu-se à presença de diferentes projetos educacionais em disputa, que podem ser identificados como a posição civil democrática e a posição produtivista em educação. Esta denominação foi cunhada por Paulo Singer (1996) e resulta bastante emblemática das visões de educação que representa.

Se acompanharmos a trajetória da elaboração da LDB, vamos observar que o texto aprovado restringe os direitos consagrados na Constituição de 1988, reformula as responsabilidades e atribuições do Estado, do mercado e da sociedade no âmbito educativo, expressando assim a alteração da correlação de forças ocorridas na sociedade.

A partir daí, as reformas estruturais do Estado, por meio de reformulaçóes de suas competências e políticas de ajuste econômica - que implicaram, entre outras coisas, novas relações entre o Estado e a sociedade -, foram realizadas com maior intensidade e amparadas pelas mudanças legais. Ao mesmo tempo, foram implementadas as reformas no âmbito educacional que permitiriam tornar, segundo os órgãos governamentais, a educação formal brasileira compatível com tal modernização geral do Estado.

O PEC mexicano em muito se assemelha ao Plano Anual de Desenvolvimento Educacional Municipal (PADEM) chileno; ao Fundo Escola brasileiro e à proposta de autonomia financeira das escolas, em Minas Gerais e outros estados brasileiros. Em que pesem algumas especificidades de operacionalização nestes programas, inclusive em suas conseqüências, em todos os casos se reposicionam a instituição escolar e o Estado na produção político-educacional. Nessa nova lógica de organização do sistema educativo busca-se instaurar dispositivos e ações na gestão/governo institucional orientados pelos princípios de flexibilidade, liberdade, diversidade, competitividade e participação.

Busca-se, por meio da política de autonomia escolar hegemônica, a ampliação da liberdade de decisão e gestão institucional dos recursos materiais e financeiros (em alguns países também dos recursos humanos) 
para dinamizar e otimizar a prática escolar, e a flexibilização das diretrizes para permitir a produção em equipe de um projeto pedagógico institucional direcionado para objetivos que tenham significado para seus usuários.

No México, em particular, isso significou uma ruptura com uma tendência educacional que já vinha sendo gestada no âmbito acadêmico e estava em vias de ser institucionalizada pelo governo. No Chile, por sua vez, isso representou a continuidade do processo de reforma liberal iniciada na época da ditadura de Pinochet (Krawczyk \& Vieira, 2003). E, no Brasil, é a implantação de uma gestão inovadora da educação, que se apresentou como uma tendência de modernização da educação e do país, e que expressa o espírito da LDB sancionada como conseqüência de uma negociação oculta ${ }^{7}$ nos bastidores e no Congresso Nacional.

$\mathrm{Na}$ passagem do âmbito empresarial para o escolar - e no marco da reconfiguração do papel do Estado na provisão e regulação educacional -, afirma-se que uma escola autônoma é aquela que tem maior liberdade de organização, gestão e ação. A liberalização da gestão escolar estaria garantindo o aumento da responsabilidade de seus atores e, portanto, a eficiência da instituição. Essa idéia de liberdade na gestão surge como possibilidade ao serem suprimidas as ações governamentais, o que obriga as instituiçôes a se tornarem autônomas.

Essa concepção de liberdade, cunhada pela matriz liberal-conservadora, foi qualificada no interior do próprio liberalismo como uma concepção negativa e regressiva, porque é individualista e encontra sua plena realização na redução ao mínimo possível do poder coletivo e estatal.

Assim, a associação de liberdade negativa à possibilidade de autonomia da instituição significa que esta última trata da liberalização da instituição para dar possibilidade aos sujeitos escolares de atuarem utilizando seus "próprios" recursos (idéias, desejos, valores, contatos sociais, recursos materiais etc.) pela ausência dos tradicionais recursos normativos e da vocação universalista do Estado na sua política financeira.

Esta proposta de liberdade e "autonomia", ainda que se defina pela ausência de uma ação governamental, é profundamente sedutora para os diferentes atores educativos. Sua sedução está amparada na idéia de poder e justiça que o senso comum costuma lhe outorgar: poder para fazer o que consideram melhor (para elaborar seus próprios projetos) e premiação ao esforço pessoal (ou institucional). E, quando os efeitos de- 
Políticas de regulação e mercantilização da educação...

sejados não são produzidos, o fracasso é interpretado como fracasso pessoal dos atores da escola, tirando do Estado qualquer tipo de responsabilidade na gestão dos problemas educacionais.

Várias pesquisas têm estudado como opera essa lógica da liberalização num contexto de extrema desigualdade e regressão social e econômica, e tem observado que os recursos da escola e da comunidade determinam as condiçôes de possibilidades concretas de suas autonomia/ liberdade; consolidando, como já vimos, formas regressivas de distribuição da educação e legitimando a segmentação do sistema educacional, sob o argumento da diferenciação (Costa, 1997; Pavan, 1998; Oliveira, 2000; entre outros).

No México não há ainda estudos que analisem as mudanças no interior das escolas, resultantes das políticas de descentralização, devido, entre outras coisas, a seu caráter incipiente. No Brasil, na década de 1980 foram construídos conceitos e proposiçôes que discutiam a gestão educacional, de alguma maneira originados por fatores internos, isto é, no marco do debate do processo de democratização naquela década, mas, talvez, sem se deter na possibilidade de estar também refletindo as mudanças que estavam acontecendo no âmbito regional e internacional. Esses conceitos e proposiçôes têm constituído o referencial de análise na produção acadêmica e no debate político até pouco tempo atrás. Só recentemente começam a ser concebidas categorias de análise que buscam dar conta dos processos de mudança ao interior da escola a partir do novo modelo de regulação social e governação educacional. Em contrapartida, as análises do processo de descentralização para a escola no Chile já apontam claramente para a existência de uma organização da educação que fomenta a desigualdade.

Assim, os questionamentos dos especialistas vão no sentido de que a descentralização, para a escola - via várias ações que tendem a uma educação orientada também pelo mercado, tais como políticas de incentivos, do "financiamento compartilhado", que permitem ao mesmo tempo a subvenção estatal à escolas particulares sem tolher a cobrança de mensalidades a seu alunado -, tem acentuado a diferença entre o grupo das escolas pobres com menor qualidade e o das escolas ricas com maior qualidade. ${ }^{8}$ Acresce-se a isto que o salário dos professores também varia conforme o desempenho de sua escola; assim, professores mais bem qualificados e mais atualizados buscam escolas em que existe a possibilidade de 
seu desempenho ser reconhecido pelos sistemas de avaliação e, portanto, de serem mais bem remunerados.

O sistema de financiamento escolar chileno é bastante complexo e pressupõe que o público não significa necessariamente gratuidade nem unicidade. Abre a possibilidade de captação de recursos materiais e humanos para a educação, advindos de vários segmentos sociais, sejam jurídicos ou físicos, e contempla um envolvimento particular das famílias na eleição e administração das escolas.

Esta reconceitualização do público é um exemplo paradigmático do processo de descentralização para o mercado. Podemos dizer que é uma forma de privatização da educação que se realiza por um conjunto de reformas que, imbricado ao processo de descentralização para a escola, busca aproximar as "decisões no mercado" (as decisões políticas) das "decisões do mercado", criando um quase-mercado ${ }^{9}$ em educação. Isto é, provocando uma gestão do sistema e da escola - com novas formas de financiamento, fornecimento e regulação diferentes das tradicionais, exclusivamente assumidas pelo Estado -, que simule o mercado.

É uma estratégia sutil para tentar gerir a tensão resultante das exigências pelo cumprimento dos direitos sociais - historicamente conquistados - com a crescente diminuição de receitas provenientes de impostos e com uma política de ajuste fiscal. Ela supõe a adoção de medidas que permitam atenuar as fronteiras entre o setor público e o setor privado, de modo que fica também menos nítida a distinção entre os direitos sociais e os direitos individuais.

A descentralização para o mercado é feita por duas vias que tendem a consolidar o espaço de quase-mercado na educação. Uma dessas vias busca, prioritariamente, descentralizar para o mercado a responsabilidade de controle e regulação educacional, e a outra pretende a descentralização da responsabilidade da oferta e universalização do serviço educativo. A primeira via pretende a constituição de um mercado de consumo de serviços educacionais, instalando na gestão da educação do sistema e da escola - uma normativa ancorada na lógica da oferta e da demanda. Ela é apresentada como a dinâmica mais adequada para a construção de um sistema educativo democrático.

Os pais têm o direito de realizar uma escolha racional da qualidade de educação para seus filhos e o dever de controlar e exigir mudanças. O sistema educativo - por intermédio das escolas - tem a obrigação de 
Políticas de regulação e mercantilização da educação...

oferecer projetos institucionais diversificados, de acordo com os interesses da população consumidora, e de prestar contas, por meio da informação dos resultados, à sociedade. Os direitos individuais do consumidor passam a prevalecer sobre os direitos sociais de educação do cidadão. Nesse sentido, têm sido elaboradas várias estratégias de informação aos pais - do tipo ranking e premiação às escolas -, fomentando a competitividade entre elas pela captação de recursos e de prestígio.

Todavia, quando esta lógica se estende como possibilidade de gerar maior eficiência da gestão orçamental, surgem, também, outras "inovações” que têm como proposta um sistema de financiamento à demanda educacional e claramente desencadeiam processos de descentralização para a escola e de privatização da educação.

Uma delas é o sistema de vouchers, ou vale-educação, destinados à distribuição de recursos para as escolas públicas e privadas. Os vales-educação são subsídios dos governos - financiados por intermédio de impostos - para as famílias poderem matricular seus filhos em escolas de sua escolha. Este sistema vem sendo implementado no Chile como uma das modalidades do "financiamento compartilhado". Mas existe também em outros países da região, tais como a Colômbia, o Porto Rico e a Guatemala; em vários países da Europa e na América do Norte. Sua proposta é estimular a competição entre as escolas públicas, e entre as escolas públicas e privadas; permitindo que as instituições ofereçam diferentes "pacotes educacionais" para satisfazer as preferências dos pais (PREAL, 1998, citado em Krawczyk, 2001).

Em alguns países tem sido incentivada, também, a idéia de autogestão. Ou seja, a comunidade se auto-administrando como forma de gestão mais livre e autônoma das escolas; através de desenhos, tais como as escolas cooperativas e as escolas charters.

A escola charter é uma modalidade de escola pública, aberta para todos, financiada com recursos públicos - atrelados à matricula - e operada por entidades independentes (por exemplo, grupo de educadores, pais de alunos e lideres comunitários). Uma de suas principais características é que tem contratos de desempenho pelos quais se regula a relação entre os operadores das escolas e os controles do ensino público. As escolas charter tiveram sua origem nos EUA, mas hoje existem também em vários países latino-americanos, tais como na província de San Luis, na Argentina e no Chile. A grande vantagem de esta modalidade seria, segundo 
o ideário da proposta, poder oferecer à comunidade a oportunidade de desenhar e operar uma grande variedade de opçôes educativas para suas crianças.

Mas esse tipo de organização, sob o véu do comunitarismo como espaço de proteção social no lugar do Estado, e de realização dos interesses coletivos, é mais uma forma de rompimento da unidade no âmbito educacional, da atomização das escolas e fonte de reprodução das desigualdades.

$\mathrm{Na}$ análise da produção recente dos organismos internacionais sobre sua avaliação da reforma educacional na região, pôde-se corroborar que a liberdade - financeira e administrativa - cada vez maior das escolas é a variável central utilizada nos estudos do Banco Mundial, do PREAL, da CEPAL e do BID, para evidenciar a eficiência e a eficácia do processo de descentralização e da reforma como um todo (Krawczyk, 2001).

A segunda via de descentralização para o mercado, identificada em muitos países - tais como Brasil e Chile -, é a transferência de funções e responsabilidades para a comunidade através do envolvimento privado e voluntário no funcionamento e na gestão da escola; transformando até mesmo a avaliação da competência da escola que passa, em vez de qualificada pelo nível de ensino, a ser qualificada por sua capacidade institucional de formular demandas e de produzir, obter e gerir recursos para satisfazê-la e, também, em atos de filantropia.

As propostas nesse sentido incentivam a idéia de que a responsabilidade pela educação e pelo bem-estar deve ser assumida por todos, e não ficar relegada ao Estado; e promovem a colaboração de diferentes setores da sociedade, filantrópicos e empresariais, ou simplesmente da vizinhança, nas escolas sob slogans do tipo "amigo da escola", "responsabilidade social", "empresa cidadā", entre outros.

No Brasil, o estado de São Paulo, principalmente, tem implementado políticas de parceria para a gestão de escolas públicas desde 1987. Os principais programas são: "Adote uma Escola" e "Parceria EmpresaEscola Pública”.

O programa "Adote uma Escola" tem como objetivo estimular empresas privadas a apoiar financeiramente escolas da rede pública, para reformas ou manutenção de seus edifícios, para incrementar o quadro de funcionários; e, eventualmente, também para complementar o salário dos docentes. 
Políticas de regulação e mercantilização da educação...

Por meio do programa "Parceria Empresa-Escola Pública", o governo estadual vem incentivando o processo de descentralização da gestão educacional, oferecendo ainda mais possibilidades desses novos atores participarem da gestão das unidades escolares, como forma de integração entre a escola e a comunidade em que esta se insere (Guimarães, 2003).

Ainda que existam poucas pesquisas que analisem a implementação nas escolas destes programas, a maioria delas afirma que a principal motivação das escolas para participar desses programas é a sua dificuldade orçamentária; e que, na relação com seus parceiros, se impõe geralmente a racionalidade empresarial e/ou filantrópica. Além disso, por parte das instâncias governamentais não existe controle das regras de jogo estabelecidas nas parcerias nem do grau de sustentabilidade. Pelo contrário, caracterizam-se pela falta de previsibilidade (ausência de compromisso em longo prazo).

Um estudo qualitativo de um projeto de parceria escola públicaempresa, em São Paulo, evidenciou que a implementação desse projeto não significou, de fato, maior participação da comunidade educativa na gestão da escola. Pelo contrário, a empresa parceira que, como diz a autora, detém o poder econômico e simbólico, foi quem acabou concentrando maior poder na gestão do projeto de parceria em questão (idem, ibid.).

É interessante observar, também, nessa pesquisa, que as ações da empresas responderam a suas próprias necessidades de trabalhadores qualificados na região. Foi realizada uma reforma para que a escola pudesse alocar um laboratório de informática, que seria utilizado na implementação de um curso profissionalizante de operador de produção.

No Chile, também existem incentivos governamentais para o investimento privado nas escolas públicas, liberando dos impostos as empresas que doassem até $2 \%$ de seus rendimentos a estabelecimentos escolares gratuitos (Figueroa, 1997).

As diretrizes relativas ao aprimoramento da gestão do financiamento público descentralizado para impedir as injustiças evidenciadas pelas instituiçôes escolares - que vem sendo testadas nos últimos anos, principalmente pelo governo chileno da Concertación - não questionam a conceitualização do ser público nem a importância da competitividade entre as escolas para produzir maior eficiência e qualidade. A racionalidade da liberdade negativa está subjacente em ambos os casos. 
O conceito de liberdade negativa e sua contrapartida liberdade positiva são interessantes para a análise da gestão escolar porque permitem distinguir duas construções antagônicas do conceito de autonomia no interior da ideologia liberal: (a) a construção ancorada na ação da escola e na negação da ação do Estado; e (b) a construção apoiada na possibilidade dos sujeitos coletivos orientarem sua vontade, seu desejo no sentido de uma finalidade coletiva. Neste último caso, estaríamos frente a uma concepção de gestão educacional e escolar que estaria indicando uma tendência à construção de um sistema e de instituições democráticos e públicos, capazes de mediar a possibilidade de escolha dos atores de ir contra a reprodução. E, ao mesmo tempo, de atores capazes de efetivar essa escolha por meio da intervenção no espaço público de produção político-educacional escolar e do conjunto do sistema educativo.

Esta é uma idéia de autonomia ligada à construção da cidadania que indica a presença de algo novo. ${ }^{10}$ Determinar o que é "o novo" é um processo coletivo, gradual, progressivo e contraditório, porque tende a igualar as condiçôes de produção dessa autonomia. Por isso, é fácil reconhecer que não estamos falando simplesmente de um problema epistemológico, mas, sobretudo, de um problema político. Por ambas as vias, o processo de descentralização para o mercado tende a gerar uma nova qualidade na relação entre escola e comunidade, que é uma relação de dependência unilateral da primeira com a segunda.

O modelo de descentralização da educação em curso na região, apresentado pelos discursos oficiais - nacional e internacional - como uma tendência moderna dos sistemas educacionais mundiais é a expressão de uma nova proposta de governação e de governabilidade da educação pública distinta da que imperou no modelo de Estado de bem-estar social. E, por isso, tem sido não só um objetivo preferencial das políticas na área, produzidas na região a partir da década de 1980, como também tem dado coesão ao conjunto das políticas educacionais nas últimas duas décadas.

Sob o discurso da necessidade de realizar uma mudança sistêmica - isto é, que afete o conjunto e a lógica do sistema educacional -, possibilitando que as necessidades, potencialidades e solidariedade dos diferentes atores confluam na melhoria da qualidade do ensino, promove-se um conjunto de mudanças estruturais no âmbito educacional que muda não apenas a qualidade do direito à educação, mas rompe a lógica das demandas sociais por educação. Assim, mesmo se propondo a democra- 
Políticas de regulação e mercantilização da educação...

tização e a descentralização, os sujeito sociais envolvidos com esta área deixam de se sentir referenciados nas políticas implantadas e contra elas reage, particularmente os profissionais da educação.

Assim, o direito à educação deixa de estar subordinado, como disse Coutinho (1994), à construção de uma sociedade democrática, entendida como a presença efetiva das condições sociais e institucionais que possibilitem ao conjunto dos cidadãos a participação ativa na formação do governo no controle da vida social. Em contrapartida, estabelece-se uma relação orgânica entre cidadania e competitividade e os atributos do direito à educação passam a ser pensados a partir de uma visão mercantilista de organização social.

\section{Recebido e aprovado em setembro de 2005.}

\section{Notas}

1. O processo de regulação social capitalista é um ordenamento normativo que media as relações entre Estado e sociedade, historicamente legítimo, que busca a solução de conflitos e compensação dos mecanismos de desigualdade e exclusão próprios do modo de produção capitalista. Esse processo tem o propósito de manter a governabilidade necessária para o desenvolvimento do sistema. Esses ordenamentos supõem uma concepção de organização social, política e econômica, a partir da qual se definem responsabilidade, competências do Estado, do mercado e da sociedade, e também tendem a desencadear processos de re-socialização.

2. O conceito de sociedade civil emerge nos anos 90 do século XX de uma forma bastante ambígua. Poderia parecer um paradoxo que a idéia de sociedade civil esteja ressurgindo num momento em que os movimentos progressistas têm sido derrotados em vários países da região. Todavia, essa revitalização do conceito se dá na sua analogia com o mercado.

3. Governação entendida como ação social de governar.

4. É interessante observar que as tendências à descentralização entre as diferentes esferas de governo, por meio principalmente da transferência do financiamento e da administração das escolas, se deram nos diferentes países em contextos históricos diferentes (na Argentina, por exemplo, realizou-se durante o governo militar) e independentemente de sua organização territorial, sejam elas federaçōes ou não, consolidando processos nacionais bastante diferentes, nos quais as características dos Estados nacionais e as condições de desenvolvimento dos municípios e províncias são aspectos fundamentais.

5. Em entrevista que nos foi concedida em março de 2002, no México.

6. A LDB é a lei maior da educação no Brasil. Ela se situa imediatamente abaixo da Constituição e define os parâmetros, os princípios e rumos que deve seguir a educação nacional.

7. Expressão cunhada por Florestan Fernandes, em oposição ao processo de elaboração dito de conciliação aberta do projeto derrotado. 
8. O financiamento compartilhado é a parceria entre os recursos do governo central (Ministério da Educação), iniciativa privada e/ou apoderados e os recursos advindos da municipalidade. A transferência dos recursos do MINEDUC para as unidades escolares se dá na forma de subsídios, mediante a apresentação do PADEM; o montante é definido conforme o desempenho dos alunos. É aí que se evidencia o círculo vicioso. As escolas sediadas nos municípios mais pobres recebem menos recursos da municipalidade que, em geral, têm mais problemas estruturais de outras ordens a resolver na comunidade. Além disso, esta, sendo mais pobre, investe menos recursos nas escolas e suas crianças e jovens têm menos acesso a informações e outros requisitos. Com isso, seu desempenho na escola é baixo, recebendo, portanto, menos subsídios governamentais.

9. As características distintivas de um quase-mercado em relação a um serviço público são: "a separação entre comprador e fornecedor e um elemento de escolha pelo usuário entre os fornecedores". No geral, os quase-mercados têm alto grau de regulamentação governamental, controlada por meio de sistemas de avaliação, fiscalização e financiamento (Levacic, 1995, citado em Whitty, 1998).

10. Uma reflexão interessante sobre a idéia de cidadania enquanto estado pleno de autonomia pode ser encontrada na entrevista realizada com Francisco de Oliveira (dez. 1999).

\section{Referências bibliográficas}

BOBBIO, N. Igualdade e liberdade. Rio de Janeiro: Ediouro, 1987.

BRUNO, L. Gestão da educação: onde procurar o democrático? In: OLIVeIRA, D.A.; Rosar, M.F.F. Política e gestão da educação. Belo Horizonte: Autêntica, 2002.

COSTA, V.L.C. (Org.). Gestão educacional e descentralização: novos padrões. São Paulo: Cortez; fUNDAP, 1997.

COUTINHO, C.N. Cidadania, democracia e educação. Idéias, São Paulo, n. 24, p. 13-26, 1994.

DUSSEL, I. La producción de la exclusión en el aula en América Latina. In: JORNADAS LOGSE, 10., 2000, Granada. La escuela y sus agentes ante la exclusión social. Granada, 2000.

EZPELETA, J. Notas para estudiar la gestión de las innovaciones educativas. 2003. (mimeo.).

FIGUEROA, A.R. Da resignação ao consentimento: privatização da educação média no Chile. Cadernos de Pesquisa, São Paulo, n. 100, p. 49-56, mar. 1997.

GIMENO, J. Poderes inestábles en educación. Madrid: Morata, 1988.

Educ. Soc., Campinas, vol. 26, n. 92, p. 799-819, Especial - Out. 2005

Disponível em <http://www.cedes.unicamp.br> 
Políticas de regulação e mercantilização da educação...

GUIMARAES, S. Parceria escola pública-empresa privada no estado de São Paulo, Brasil. 2003. Dissertação (Mestrado) - Faculdade Latino-Americana de Ciências Sociais (fLACSO), Buenos Aires.

KRAWCZYK, N.R. A gestão escolar: um campo minado...; análise das propostas de 11 municípios brasileiros. Educação \& Sociedade, Campinas, v. 20, n. 67, p. 112-150, ago. 1999.

KRAWCZYK, N.R. A sustentabilidade da reforma educacional em questão: a posição dos organismos internacionais. Revista Brasileira de Educação, Belo Horizonte, n. 19, jan./abr. 2001.

KRAWCZYK, N.R. Em busca de uma nova governabilidade na educação. In: Oliveira, D.A.; Rosar, M.F.F. Politica e gestão da educação. Belo Horizonte: Autêntica, 2002.

KRAWCZYK, N.R. A escola média: um espaço sem consenso. Cadernos de Pesquisa, São Paulo, n. 120, p.169-202, nov. 2003.

KRAWCZYK, N.R.; VIEIRA, V.L. A reforma educacional no México e no Chile: apontamentos sobre as rupturas e continuidades. Educar em Revista, Curitiba, n. 22, 2003.

KRAWCZYK, N.R.; VIEIRA, V.L. Um estudo sobre o estado da arte da reforma educacional na década de 90 na América Latina: Brasil, Argentina, Chile e México. Relatório de pesquisa, FAPESP, maio 2005.

MUNíM, H. (Comp.). La autonomia de la escuela: libertad y equidad?; un recorrido por la discusión alemana de los años noventa. Buenos Aires: Aique, 1999.

OLIVEIRA, D.A. Educação básica: gestão do trabalho e da pobreza. Petrópolis: Vozes, 2000.

OLIVEIRA, F. O que é formação para a cidadania?; entrevista com Francisco de Oliveira, realizada por Silvio Caccia Bava. São Paulo: Instituto Pólis, 1999. Disponível em: <www.dhnet.org.br/direitos/sos/textos/ coliveira.htm > Acesso em: set. 2005.

PAVAN, R. Autonomia do ensino no estado de São Paulo: o caso de Santos e Jundiaí. 1998. Dissertação (Mestrado) - Pontifícia Universidade Católica de São Paulo, São Paulo. 
PEREYRA, M. et al. (Comp.). Globalización y descentralización de los sistemas educativos. Barcelona: Pomares-Corredor, 1996.

SINGER, P. Poder, política e educação. Revista Brasileira de Educação, Belo Horizonte, n. 1, p. 5-15, 1996.

TEDESCO, J.C. Educación y sociedad en la Argentina (1880-1900). Buenos Aires: Centro Editor de América Latina, 1982.

TRAGTENBERG, M. Relações de poder na escola. Educação \& Sociedade, Campinas, v. 7, n. 20, p. 40-45, jan./abr. 1985.

WHITTI, G. Controle do currículo e quase-mercados: a recente reforma educacional na Inglaterra e no País de Gales. In: Warde, M. (Org.). Novas políticas educacionais: críticas e perspectivas. São Paulo: PUC, 1998. p. 193-213. 